\title{
Introduction of Professor Daya Reddy
}

\author{
Brian Warner \\ Department of Astronomy, University of Cape Town, Rondebosch 7700, \\ South Africa
}

I found many reasons why I should not call on Professor Reddy to open an astrophysical conference.

First, he is a Dean, and in the usual perception of a University, with the faculty staff looked upon as gentle herbivores and the students as their parasites, there is only one carnivore, and that is the Dean. Certainly in many countries this hierarchy applies to funding, with massive overheads levied on all grants honestly obtained, the proceeds of which go to supporting the University Administration, including support of a Dean's excessive staff. But in the UCT Faculty of Science, although there is overhead of $10 \%$ levied on incoming grants, this is not consumed by the Dean - it is used for redistribution, taking from the poor and giving to the totally impoverished. Furthermore, our Dean spends time fighting other sectors of the University to try to get more funds for his herbivores. So I have no reason for concern on that account.

Then there is the perception that the Dean is the Captain of a ship - a slave ship - running round with knotted ropes, cats of nine lives or whatever, extracting the last drop of productivity from his bovine staff. But even if Professor Reddy thinks he recognises himself in this description, it is not the Faculty's perception - which is that of a Admiral who leads from the front, a research scientist who has reached the highest levels in the national ranking system since he was appointed Dean, showing him to be accepted internationally as a leader in his field.

So now I come to the question of his research field - and here I hesitated a long time, because he is a world authority on non-Newtonian fluid flow. A Non-Newtonian! Given the respect in which we all hold what the Cambridge astrophysicists call their "late lamented colleague", should I invite such a person to an astrophysics meeting? And then I thought that, proud as we are of the purity of working with Perfect Gases, we also have to dirty our hands with Degenerate Gases - so who are we to be choosy?

Another thought crossed my mind: Professor Reddy might upstage we mere astrophysicists. I have attended a lecture of his in which he covered the blackboard with tensors that describe the motion of deformable bodies, such as blood corpuscles, as they pass through deformable channels, such as veins and arteries. Red-blooded astrophysicists we may be, but I am not sure that we are ready to be shown science that is actually applicable and useful!

Then another important point - Professor Reddy is Chairman of the Board of the National Research Foundation, the research funding agency for which few scientists and engineers in South Africa have much affection. But then I thought - would I boycott the Chairman of the Board of a lunatic hospital - and the 
answer, particularly because of the aptness of the analogy, is obviously No - one hopes that a Board is composed of sane people who are struggling to make a difference. And in any case, such experience would surely come in helpful when dealing with astrophysicists.

Then there was a personal hurdle to overcome - Professor Reddy has a PhD from Cambridge University, whereas I am an Oxford man. But again, who am I to be choosy - I am told that Cambridge has on occasion been mentioned in astrophysical dispatches.

So eventually I had no reservations in inviting my good friend and colleague Daya Reddy to open this Colloquium on Magnetic Cataclysmic Variable Stars. 